Article

\title{
An Advanced Mode of Antioxidants Delivery System Effective in the Treatment of ROS and Skin Permeation of The Cosmetic Formulations - The Possible Application of Clove Oil, Eugenol and New Eugenol Derivative
}

\author{
Edyta Makuch 1,*, Anna Nowak 2, Andrzej Günther 1, Robert Pełech 1, Łukasz Kucharski ${ }^{2}$, \\ Wiktoria Duchnik ${ }^{2}$ and Adam Klimowicz ${ }^{2}$ \\ 1 West Pomeranian University of Technology, Szczecin, Faculty of Chemical Technology and Engineering, \\ Department of Chemical Organic Technology and Polymeric Materials, Pulaskiego 10, 70-322 Szczecin, \\ Poland; emakuch@zut.edu.pl (E.M.); andrzej.gunther@zut.edu.pl (A.G.); rpelech@zut.edu.pl (R.P.); \\ 2 Pomeranian Medical University in Szczecin, Department of Cosmetic and Pharmaceutical Chemistry, \\ Powstańców Wielkopolskich Ave. 72, 70-111 Szczecin, Poland; anowak@pum.edu.pl (A.N.); \\ lukasz.kucharski@pum.edu.pl (Ł.K.); wiktoria.duchnik@pum.edu.pl (W.D); adam.klimowicz@pum.edu.pl \\ (A.K.) \\ * Correspondence: emakuch@zut.edu.pl (E.M.); Tel.: +48-91-449-41-48 (E.M.)
}

\begin{abstract}
The main focus of this work is to extend the knowledge about the complexity of issues of oxidative stress. Natural compounds play a serious role in multiple aspects of both human, leading to clear health-promoting effects. This work is focused on the potential application cosmetic formulations containing including but not limited to of clove water and isolated clove oils on their aid in the control of the diseases. The aim of our work was to prepare to evaluate cosmetic formulations containing clove oil, eugenol or new eugenol ester derivative (eugenyl dichloroacetate - EDChA) but also cosmetic formulations containing the aqueous phase obtained after separation of essential oil following the clove buds steam distillation. To evaluate the antioxidants transdermal delivery system, in vitro permeation experiments in a Franz diffusion cell were performed using pig skin. The antioxidative capacity of the cosmetic formulations obtained was determined by the DPPH free radical reduction method. In the next stage, the antioxidant activity (DPPH, ABTS, and Folin-Ciocalteu methods) of the fluid that penetrated through pig skin and of the fluid obtained after skin extraction, were also evaluated. For comparison, studies of cosmetic formulation containing alone dichloroacetic acid (DChAA) were as well carried out. The obtained cosmetic formulations were characterized by of antioxidant activity estimated after 24 hours of conducting the experiment, which indicates long-term protection against reactive oxygen species (ROS) in the deeper layers of the skin. The results of this work contribute to the development of cosmetic formulations with antioxidant potential, emphasizing that the water phases are waste from the process of cloves steam distillation and are not used to prepare cosmetic formulations. The use of waste water from the clove buds steam distillation process is environmentally friendly and not allows us to waste, containing however valuable biologically active compounds (furfural, methyl salicylate, 4-allilofenol, eugenol, $\alpha$ - and $\beta$-caryophyllene, eugenyl acetate, $\beta$-caryophyllene oxide). Together, these results suggest that cosmetic formulations may be potential drug candidates for chemopreventive, antineoplastic and antimutagenic therapy.
\end{abstract}

Keywords: antioxidants for the treatment of ROS; new ester of eugenol; cosmetic formulations with clove water; skin penetration; Franz cell 


\section{Introduction}

Clove oil (Eugenia caryophyllata) is known for its antibacterial and anti-inflammatory properties [1]. Moreover, it show antineoplastic and antimutagenic properties and is helpful in digestion problems [2]. Currently, alternative and complementary methods of cancer treatment are being sought. The anticancer activity of clove oil involves many mechanisms, including cytotoxic, antiproliferative, anti-mutagenic and detoxifying effects. Due to its antioxidant properties, clove oil also has a chemopreventive effect. The anticancer effect of clove oil is associated with a wide range of compounds contained in this oil, such as: eugenol, methyleugenol, eugenyl acetate, $\alpha$ - and $\beta$ caryophyllene, 4-allyl-2-methoxybenzoic aldehyde, $\alpha$ - and B-caryophyllene oxide, kopaen, kadinen, isoeugenol. These compounds have a lipophilic character and low molecular weight, therefore they can penetrate cell membranes, leading to a decrease in ATP production and loss of mitochondrial potential. These changes may lead to cancer cell death [1-10].

In view of the content of phenolic compounds in clove oil it can be used for chemopreventive purposes. Eugenol reduced the incidence of N-methyl-N'-nitro-N-nitrosoguanidine gastric tumours by suppressing NF- $\kappa \mathrm{B}$ (nuclear factor) activation and modulating the expression of NF- $\kappa \mathrm{B}$ target genes that regulate cell proliferation and cell survival. The targeting of NF- $\kappa B$ signaling pathway by eugenol may have a significant impact on chemopreventive and therapeutic approaches for cancer $[8,11]$.

The antioxidant effect of eugenol and its esters is based on prevention of free radicals formation, repairing oxidative damage and elimination of the damaged particles [12-18]. In the human body, the oxidative-antioxidant balance is crucial as it maintains the integrity and functionality of the cell membrane $[19,20]$. In the body ROS can cause a lot of potential damage. It is widely recognized that reactive oxygen species contribute to the aging of the skin, the outer barrier of our body. Moreover, many tissues inside our organism are also subjected to ROS. In fact, the human body is exposed to both endogenous and exogenous ROS effects. These compounds, which cause oxidative stress, are responsible for oxidative modifications of polyunsaturated fatty acids and nucleic acids (and as a consequence, to structural changes in cell membranes as well as to DNA damage) [20-27].

The studies showed that $\beta$-caryophyllene induces a repeated cancer response to cytotoxic drugs facilitating the passage of paclitaxel through the membrane of cancer cells, thus enhancing the anticancer activity of this compound [28]. Eugenol enhances the action of chemotherapeutic agents and induces apoptosis of cervical cancer cells without toxicity to healthy cells [29]. Additionally, eugenol, eugenyl acetate, $\beta$-caryophyllene, $\beta$-caryophyllene oxide were also tested in animal models for antiangiogenic effects. The results of several studies showed that these compounds are characterized by antiangiogenic activity against different lines of cancer cells and inhibit melanoma growth and lung metastases in mice $[1,28,30]$.

As a result of our previous research, eugenyl dichloroacetate was obtained as a result of reaction of eugenol with dichloroacetic acid chloride. The selectivity of the conversion to EDChA as well as the conversion of eugenol were determined by the gas chromatography (GC), while the molar mass of the obtained product was confirmed based on the mass spectrum (GC-MS). The most important band associated with the presence of an ester group in the structure of the obtained ester was identified by infrared spectroscopy. The unequivocal confirmation of the structure of new eugenol ester derivative was carried out by NMR. The antioxidative activity of eugenol and its ester was evaluated by the spectrophotometric method, whereas the values of the n-octanol/water partition coefficient $(\mathrm{P})$ were used to evaluate the lipophilicity. The penetration of these compounds through pig skin using the Franz diffusion cell and their accumulation in the skin were also evaluated. Moreover, the antioxidant potential of solutions applied to the skin after 24 hours penetration through the skin as well as the activity of the skin after penetration studies was assessed [18].

The aim of our work was to prepare to evaluate cosmetic formulations containing clove oil, eugenol or new eugenol ester derivative (EDChA) but also cosmetic formulations containing the aqueous phase obtained after separation of essential oil following the clove buds steam distillation. The results of this work contribute to the development of cosmetic formulations with antioxidant potential, emphasizing that the water phases are waste from the process of cloves steam distillation 
and are not used to prepare cosmetic formulations. We evaluated the antioxidant activity and their penetration capacity (through pig skin using the Franz diffusion cell) of the obtained cosmetic formulations. For comparison also studies with DChAA was done. Moreover, the ecological aspect of our research seems to be of importance. The use of waste water from the clove buds steam distillation process is environmentally friendly and allows us to waste, containing however valuable biologically active compounds (furfural, methyl salicylate, 4-allilofenol, eugenol, $\alpha$ - and $\beta$ caryophyllene, eugenyl acetate, $\beta$-caryophyllene oxide).

\section{Materials and Methods}

\subsection{Chemicals}

To prepare the studied cosmetic formulations vaseline, and cholesterol (Coel. Cracow), beeswax (supplied by Zrob Sobie Krem distributor), clove buds of Syzygium aromaticum from Madagascar and Indonesia (Bolinero, Prymat), eugenol p.a. (Keten) and distilled water.

To determine of antioxidant activity and skin permeation of active components of prepared cosmetic formulations (eugenol, EDChA, DChAA, clove oil, clove water), 2,2-diphenyl-1picrylhydrazyl (DPPH), 6-hydroxy-2,5,7,8-tetramethylchroman-2-carboxylic acid (trolox) were purchased from Sigma-Aldrich (USA), ethanol $(96 \% \mathrm{v} / \mathrm{v})$, acetone, methanol, sodium chloride, potassium chloride (all of the analytical grade) were from Chempur (Poland) and acetonitrile for HPLC was purchased from J.T. Baker.

\subsection{Measurement of the Antioxidant Capacity of Clove Oil, Clove Water, Eugenol and its New Ester}

Antioxidative activity of ethanolic solutions of eugenol and its new derivative (EDChA) were determined using spectrophotometric method based on DPPH radical reduction as described elsewhere $[18,31]$. The absorbance at the wavelength of $517 \mathrm{~nm}$ was measured using Spectroquant Pharo 300 (Merck, Germany). The antioxidant activity of eugenol and its ester was measured as follows: to $2850 \mu \mathrm{l}$ of DPPH ethanolic solution (absorbance at $517 \mathrm{~nm} 1.00 \pm 0.02$ ) $150 \mu \mathrm{l}$ of the sample (containing one of the tested compound) was added. The tube was wrapped in aluminum foil, sealed with a stopper and incubated for 10 minutes at room temperature. Each sample was prepared in triplicate. After incubation, spectrophotometric measurements were carried out at $517 \mathrm{~nm}$. Solvent applied to obtain extracts was used as reference. The results were expressed as radical scavenging activity (RSA) [19]. For each studied compound calibration curve of RSA vs. concentration was prepared to calculate $\mathrm{IC}_{50}$, i.e. the concentration of the compound reducing $50 \%$ of free radicals

Moreover, antioxidant activity of clove oil extracted from clove buds by steam distillation and water obtained after steam distillation was evaluated by DPPH method after 10 to 60 minutes of incubation $[18,31]$.

\subsection{Method of Cosmetic Formulations Containing of Clove Oil, Eugenol and EDChA}

Cosmetic formulations were prepared as follows: beeswax $(0.032 \mathrm{~g})$, cholesterol $(0.176 \mathrm{~g})$ and vaseline $(3.647 \mathrm{~g})$ were put to glass beaker. The beaker was placed in water bath $\left(70^{\circ} \mathrm{C}\right)$ to dissolve the contents. To the second beaker distilled water $(5.882 \mathrm{~g})$ and the appropriate amount of either eugenol, its ester or clove oil were added $(1.000 \% \mathrm{w} / \mathrm{w})$ and mixed using the recipe mixer at $1375 \mathrm{rpm}$ (Eprus ${ }^{\circledR}$ U500) to achieve a uniform consistency. In the next stage, the content of the second beaker was added to the first beaker, and then were mixed using the recipe mixer to achieve a uniform consistency of the emulsion.

In addition, another form containing aqueous phase obtained after the cloves distillation (5.882g) instead of distilled water was also prepared and evaluated. Usually water phases are waste from the process of cloves distillation and are not used in cosmetic formulations.

Moreover, for comparison purpose, cosmetic vehicle without active substance were prepared, into which either eugenol, EDChA or clove oil was introduced manually. 


\subsection{Measurement of the Antioxidant Capacity of Cosmetic Formulations and Skin Permeation Studies of Cosmetic Formulations}

Antioxidant activity of cosmetic formulations were evaluated using slightly modified DPPH method. The procedure was as follows: to $2850 \mu \mathrm{l}$ of DPPH radical solution in acetone (its absorbance at $\lambda=517 \mathrm{~nm}$ was $1.00 \pm 0.02) 150 \mu \mathrm{l}$ of the acetone solution containing the tested formulation (in the concentration of $10.0 \% \mathrm{w} / \mathrm{w}$ ). The tube was wrapped in aluminum foil and sealed with a stopper and then incubated for 10 and up to 60 minutes at room temperature. Each samples was prepared in triplicate. After incubation, spectrophotometric measurements were carried out at the abovementioned wavelength.

The penetration of cosmetic formulations containing eugenol, EDChA and DChAA were assessed in a Franz diffusion chamber consisted of a $2 \mathrm{ml}$ donor chamber and an $8 \mathrm{ml}$ acceptor chamber. The penetration area was $1 \mathrm{~cm}^{2}$. The acceptor fluid, mixed with a magnetic stirrer, was a PBS (phosphate-buffered saline, $\mathrm{pH}$ 7.4) solution that maintained the physiological $\mathrm{pH}$. The acceptor chamber was kept at a constant temperature of $37 \pm 0.5^{\circ} \mathrm{C}$ with the VEB MLW Prüfgeräte-Werk type 3280 thermostat. Before starting the test, Franz diffusion cells were allowed to equilibrate at $37^{\circ} \mathrm{C}$ for 15 minutes. Porcine skin was used for the study due to its similar permeability properties to human skin. The skin was from a local slaughterhouse. A fresh portion of skin from the abdomen was washed several times with a solution of PBS. Skin with a thickness of $0.5 \mathrm{~mm}$ was cut with a dermatome, and then it was wrapped in aluminum foil and frozen at $-20{ }^{\circ} \mathrm{C}$ for a maximum of 3 months. This freezing time ensured the stability of the skin barrier properties [32]. Before the examination, the skin was thawed at room temperature for about 30 minutes, and then it was soaked in a PBS solution for 15 minutes to hydrate it [33]. In the next stage, the skin was mounted in Franz diffusion cells. The integrity of skin was checked one hour after its installation in the Franz diffusion chamber (SES GmbH Analyze Systeme, Germany). For this purpose skin impedance was measured using an LCR 4080 meter (Conrad Electronic, Germany) operating in parallel mode at $120 \mathrm{~Hz}(\mathrm{k} \Omega$ error $<0.5 \%$ ). To make the measurement, the tips of the probes were immersed in the donor and acceptor chambers filled with the PBS solution [34]. Membranes with an electrical resistance of $>3 \mathrm{k} \Omega$, corresponding to the resistance measured for human skin, were used in the study [35].

Cosmetic formulations (1.000g) containing of the test compound (eugenol, EDChA and DChAA) were placed in the donor chamber. All donor chambers were closed with a plastic stopper to prevent excessive evaporation of the formulation. The described tests were carried out up to 24 hours. An aliquot of $0.3 \mathrm{ml}$ of the solution in the acceptor chamber was taken at specified intervals ( $30 \mathrm{~min}, 1 \mathrm{~h}$, $2 \mathrm{~h}, 3 \mathrm{~h}, 4 \mathrm{~h}, 5 \mathrm{~h}, 8 \mathrm{~h}$ and $24 \mathrm{~h}$ ), and then supplemented with a fresh portion of buffer of the same $\mathrm{pH}$ [34]. The samples were analyzed by high-performance liquid chromatography (HPLC) with a UV detector (Knauer, Berlin, Germany). The components tested were separated on a $125 \times 4$ mm column containing Hyperisil ODS; particle size $5 \mu \mathrm{m}$. The flow rate of the mobile phase, consisted of acetonitrile, water, and $\mathrm{MeOH}(28: 64: 8$, by vol), was $1 \mathrm{ml} / \mathrm{min}$. Twenty microliters of each analyzed sample was injected onto the column.

After completion of penetration experiment, the skin was extracted to estimate the residual amount of tested active ingredients accumulated in it. The antioxidant activity of the obtained extracts was also tested using methods previously described [31,32]. Extraction was carried out as follows: after the experiment was completed, the Franz diffusion chambers were dismantled, while the skin surface was washed three times with an aqueous solution of sodium lauryl sulfate (at a concentration of $0.5 \% \mathrm{w} / \mathrm{w})$ to elute of the test compound. A patch $\left(1 \mathrm{~cm}^{2}\right.$ diffusion surface) was cut from the skin prepared in this way, dried at room temperature, and then weighed and cut into smaller pieces. Then, $2 \mathrm{ml}$ of concentrated methanol was added, and extraction was carried out for 24 hours at $4{ }^{\circ} \mathrm{C}$. After 24 hours of incubation, the skin was homogenized (for 3 minutes) using a homogenizer (IKA®T18 digital ULTRA TURRAX, Germany). The extracts obtained were then centrifuged at 3500 rpm for 5 minutes. The supernatant was analyzed by HPLC to determine the content of active ingredients, while tests on the antioxidant activity of the obtained extracts were carried out using the DPPH, Folin-Ciocalteau, and ABTS methods. 
The cumulative mass of active substance $(\mu \mathrm{g})$ permeating into the receptor chamber was calculated based on the concentrations of compounds in receptor fluid determined by HPLC. The permeation rate was determined based on the amount of permeation of a compound over a given period $\left(\mu \mathrm{g} / \mathrm{cm}^{2} / \mathrm{h}\right)$. The accumulation of compounds in the skin was calculated by dividing the amount of compound obtained after skin extraction; the results are given in $\mu \mathrm{g} / \mathrm{cm}^{2}$ of skin [18]. Statistical calculations were done using Statistica 13 PL software (StatSoft, Polska). The results were evaluated using one-way analysis of variance (ANOVA). Significant differences between the permeation of individual compounds were evaluated using Tukey post-hoc test. Probabilities $p<0.05$ were considered to be statistically significant. Results are presented as the mean \pm standard deviation (SD).

The antioxidant activity of acceptor fluid taken after 24 hours of penetration, and solutions obtained after skin extraction performed after the experiment was determined using the DPPH (according to the procedure described above) [18, 31], ABTS [18, 36] and Folin-Ciocalteau [18, 19] methods. The ABTS assay is based on the generation of a blue/green ABTS radical, which is applicable to both hydrophilic and lipophilic antioxidant systems; whereas DPPH assay uses a radical dissolved in organic media and is, therefore, applicable to hydrophobic systems [37].

First, an aqueous solution of potassium persulfate $(2.45 \mathrm{mM})$ was prepared, to which an appropriate amount of ABTS reagent was introduced to obtain a $7 \mathrm{mM}$ solution of ABTS in an aqueous solution of potassium persulfate. The solution prepared in this way was incubated at $4{ }^{\circ} \mathrm{C}$ for 24 hours and then diluted with methanol $(50 \% \mathrm{v} / \mathrm{v})$ to obtain an absorbance of $1.000 \pm 0.020$ at 734 $\mathrm{nm}$. The antioxidant activity of acceptor fluid and solutions obtained after skin extraction was measured as follows: $2500 \mu \mathrm{l}$ of working ABTS solution and $25 \mu \mathrm{l}$ of ethanolic solution of tested antioxidant were mixed in spectrophotometric cuvette. The samples prepared in triplicate were incubated for 6 minutes at room temperature. After this time, the absorbance at $734 \mathrm{~nm}$ was measured.

To determine the total content of phenolic compounds in the tested samples the method based on the use of the Folin-Ciocalteu reagent in alkaline medium was applied. The reaction is based on the spectrophotometrically recorded color change of the test solution from yellow to blue. FolinCiocalteu reagent was diluted tenfold with water in a dark bottle and incubated at room temperature for 60 minutes. The antioxidant activity of acceptor fluid and solutions obtained after skin extraction was measured as follows: $1350 \mu \mathrm{l}$ of distilled water and $1350 \mu \mathrm{l}$ of sodium carbonate solution $(0.01$ $\mathrm{mol} / \mathrm{dm}^{3}$ ) were mixed in spectrophotometric cuvette with $150 \mu \mathrm{l}$ of the prepared Folin-Ciocalteu solution and $150 \mu \mathrm{l}$ of an ethanol solution containing the tested cosmetic formulation. The cuvette was sealed with a stopper and incubated for 15 minutes at room temperature. All the samples were prepared in triplicate. After this time, spectrophotometric measurements were carried out at $750 \mathrm{~nm}$ using water as a reference.

\section{Results and Discussion}

\subsection{Measurement of the Antioxidant Capacity of Eugenol and New Ester}

Table 1 presents antioxidant activity of eugenol, its ester derivative and dichloroacetic acid, carried out by the DPPH method. 
Table 1. Antioxidant activity of eugenol, EDChA and DChAA.

\begin{tabular}{|c|c|c|c|}
\hline \multirow{3}{*}{$\begin{array}{l}\text { Concentration of } \\
\text { antioxidant } \\
(\% \mathrm{w} / \mathrm{v})\end{array}$} & \multicolumn{3}{|c|}{ Antioxidant activity (DPPH method): } \\
\hline & Eugenol* $^{*}$ & $\mathrm{EDChA}^{*}$ & DChAA $^{*}$ \\
\hline & \multicolumn{3}{|c|}{ \%RSA } \\
\hline 0.006 & $49.90 \pm 0.003$ & $72.85 \pm 0.001$ & \multirow{28}{*}{ n.a. } \\
\hline 0.007 & $55.00 \pm 0.002$ & $72.90 \pm 0.002$ & \\
\hline 0.010 & $75.02 \pm 0.000$ & $72.95 \pm 0.000$ & \\
\hline 0.030 & $77.49 \pm 0.001$ & $72.95 \pm 0.000$ & \\
\hline 0.050 & $81.16 \pm 0.000$ & $72.95 \pm 0.001$ & \\
\hline 0.100 & $82.48 \pm 0.000$ & $72.08 \pm 0.000$ & \\
\hline 0.150 & $85.98 \pm 0.000$ & $70.83 \pm 0.000$ & \\
\hline 0.200 & $85.17 \pm 0.000$ & $68.96 \pm 0.001$ & \\
\hline 0.250 & $87.30 \pm 0.000$ & $68.95 \pm 0.000$ & \\
\hline 0.500 & $87.91 \pm 0.000$ & $68.91 \pm 0.001$ & \\
\hline 1.000 & $88.72 \pm 0.002$ & $65.90 \pm 0.000$ & \\
\hline 1.500 & $88.93 \pm 0.001$ & $65.83 \pm 0.001$ & \\
\hline 2.000 & $88.22 \pm 0.001$ & $64.87 \pm 0.000$ & \\
\hline 2.500 & $90.25 \pm 0.001$ & $64.04 \pm 0.001$ & \\
\hline 3.000 & $90.60 \pm 0.000$ & $62.76 \pm 0.001$ & \\
\hline 3.500 & $90.60 \pm 0.001$ & $59.96 \pm 0.001$ & \\
\hline 4.000 & $90.71 \pm 0.001$ & $58.23 \pm 0.000$ & \\
\hline 5.000 & $90.60 \pm 0.001$ & $58.53 \pm 0.000$ & \\
\hline 6.000 & $91.32 \pm 0.000$ & $56.74 \pm 0.001$ & \\
\hline 7.000 & $91.57 \pm 0.001$ & $56.62 \pm 0.001$ & \\
\hline 8.000 & $91.62 \pm 0.000$ & $53.46 \pm 0.001$ & \\
\hline 9.000 & $92.48 \pm 0.001$ & $51.75 \pm 0.001$ & \\
\hline 10.000 & $92.64 \pm 0.001$ & $50.01 \pm 0.000$ & \\
\hline 15.000 & $93.60 \pm 0.001$ & $45.21 \pm 0.001$ & \\
\hline 20.000 & $94.92 \pm 0.001$ & $33.49 \pm 0.001$ & \\
\hline 25.000 & $95.84 \pm 0.001$ & $24.50 \pm 0.001$ & \\
\hline 30.000 & $97.05 \pm 0.001$ & $16.31 \pm 0.001$ & \\
\hline 50.000 & $97.05 \pm 0.001$ & $16.31 \pm 0.002$ & \\
\hline $\mathrm{IC}_{50}(\mu \mathrm{M})$ & $* * 6.09$ & $* * * 4275.98$ & - \\
\hline \multicolumn{4}{|c|}{$\begin{array}{l}{ }^{*} \text { Mean } \pm \text { S.D. }(\mathrm{n}=3) \\
\text { ** density determined experimentally }\left(1.00 \mathrm{~g} / \mathrm{cm}^{3}\right), \\
\text { *** density determined experimentally }\left(1.15 \mathrm{~g} / \mathrm{cm}^{3}\right)\end{array}$} \\
\hline
\end{tabular}

Table 2 presents the antioxidant activity of the essential oil and clove water obtained after steam distillation of cloves from Indonesia.

Table 2. Time course evolution of the antioxidant activity of the clove oil and clove water evaluated with DPPH method.

\begin{tabular}{ccc}
\hline \multirow{2}{*}{$\begin{array}{c}\text { Time } \\
(\mathbf{m i n})\end{array}$} & \multicolumn{2}{c}{ Antioxidant activity (DPPH method) } \\
\cline { 2 - 3 } & \multicolumn{2}{c}{ \% RSA } \\
\cline { 2 - 3 } & ${ }^{\mathrm{a} C l o v e ~ o i l ~(1.000 \% \mathrm{w} / \mathrm{v})}$ & ${ }^{\mathrm{b}}$ Clove water \\
\hline $\mathbf{1 0}$ & $\mathbf{8 9 . 0 4} \pm \mathbf{0 . 0 0 1}$ & $\mathbf{3 3 . 0 2} \pm \mathbf{0 . 0 0 0}$ \\
\hline 11 & $89.09 \pm 0.001$ & $32.00 \pm 0.005$ \\
\hline 12 & $89.15 \pm 0.002$ & $31.79 \pm 0.003$ \\
\hline 13 & $89.04 \pm 0.001$ & $31.74 \pm 0.002$ \\
\hline 14 & $89.20 \pm 0.002$ & $31.58 \pm 0.001$ \\
\hline 15 & $89.04 \pm 0.001$ & $31.48 \pm 0.000$ \\
\hline 16 & $89.09 \pm 0.001$ & $31.38 \pm 0.001$ \\
\hline 17 & $89.04 \pm 0.001$ & $31.28 \pm 0.002$ \\
\hline 18 & $89.09 \pm 0.003$ & $31.07 \pm 0.004$ \\
\hline
\end{tabular}




\begin{tabular}{|c|c|c|}
\hline 19 & $88.94 \pm 0.000$ & $30.97 \pm 0.005$ \\
\hline 20 & $89.04 \pm 0.001$ & $30.86 \pm 0.006$ \\
\hline 21 & $89.09 \pm 0.000$ & $30.76 \pm 0.007$ \\
\hline 22 & $89.15 \pm 0.000$ & $30.66 \pm 0.008$ \\
\hline 23 & $89.15 \pm 0.000$ & $30.56 \pm 0.008$ \\
\hline 24 & $89.09 \pm 0.000$ & $28.60 \pm 0.001$ \\
\hline 25 & $89.04 \pm 0.001$ & $27.06 \pm 0.001$ \\
\hline 26 & $89.09 \pm 0.000$ & $25.51 \pm 0.001$ \\
\hline 27 & $89.15 \pm 0.002$ & $23.97 \pm 0.001$ \\
\hline 28 & $89.30 \pm 0.002$ & $23.10 \pm 0.001$ \\
\hline 29 & $89.45 \pm 0.003$ & $21.55 \pm 0.001$ \\
\hline 30 & $89.41 \pm 0.002$ & $19.44 \pm 0.001$ \\
\hline 31 & $89.40 \pm 0.002$ & $18.62 \pm 0.001$ \\
\hline 32 & $89.51 \pm 0.003$ & $18.83 \pm 0.002$ \\
\hline 33 & $89.52 \pm 0.002$ & $18.62 \pm 0.001$ \\
\hline 34 & $89.51 \pm 0.002$ & $18.47 \pm 0.002$ \\
\hline 35 & $89.52 \pm 0.003$ & $18.36 \pm 0.001$ \\
\hline 36 & $89.50 \pm 0.002$ & $17.59 \pm 0.000$ \\
\hline 37 & $89.51 \pm 0.002$ & $17.59 \pm 0.001$ \\
\hline 38 & $89.53 \pm 0.003$ & $17.59 \pm 0.000$ \\
\hline 39 & $89.61 \pm 0.001$ & $17.59 \pm 0.000$ \\
\hline 40 & $89.51 \pm 0.002$ & $17.49 \pm 0.000$ \\
\hline 41 & $89.76 \pm 0.001$ & $17.44 \pm 0.000$ \\
\hline 42 & $89.76 \pm 0.002$ & $17.39 \pm 0.001$ \\
\hline 43 & $89.87 \pm 0.001$ & $17.59 \pm 0.001$ \\
\hline 44 & $89.92 \pm 0.003$ & $17.39 \pm 0.002$ \\
\hline 45 & $90.02 \pm 0.001$ & $17.28 \pm 0.000$ \\
\hline 46 & $91.36 \pm 0.001$ & $17.18 \pm 0.001$ \\
\hline 47 & $91.72 \pm 0.000$ & $17.13 \pm 0.001$ \\
\hline 48 & $91.72 \pm 0.001$ & $16.98 \pm 0.001$ \\
\hline 49 & $91.87 \pm 0.001$ & $16.92 \pm 0.002$ \\
\hline 50 & $91.77 \pm 0.001$ & $16.87 \pm 0.002$ \\
\hline 51 & $92.54 \pm 0.000$ & $16.82 \pm 0.001$ \\
\hline 52 & $92.70 \pm 0.001$ & $16.72 \pm 0.000$ \\
\hline 53 & $92.80 \pm 0.000$ & $16.82 \pm 0.001$ \\
\hline 54 & $93.67 \pm 0.001$ & $16.67 \pm 0.001$ \\
\hline 55 & $93.83 \pm 0.001$ & $16.72 \pm 0.001$ \\
\hline 56 & $94.80 \pm 0.001$ & $16.67 \pm 0.001$ \\
\hline 57 & $96.14 \pm 0.001$ & $16.67 \pm 0.001$ \\
\hline 58 & $98.87 \pm 0.000$ & $16.72 \pm 0.003$ \\
\hline 59 & $98.92 \pm 0.001$ & $16.77 \pm 0.004$ \\
\hline 60 & $98.92 \pm 0.001$ & $16.77 \pm 0.004$ \\
\hline
\end{tabular}

* Mean \pm S.D. $(\mathrm{n}=3)$,

${ }^{a}$ waste water from the cloves from Indonesia containing: furfural $0.98 \%$, benzyl alcohol $0.32 \%$, methyl salicylate $0.27 \%$, 4-allilofenol $0.41 \%$, eugenol $94.45 \%$, $\beta$-caryophyllene $1.21 \%$, $\alpha$-caryophyllene $0.20 \%$, eugenyl acetate $2.14 \%$,

bthe essential oil from the cloves from Indonesia containing: 4-allilofenol 0.31\%, eugenol 97.69\%, $\beta$ caryophyllene $0.77 \%$, eugenyl acetate $1.23 \%$,

waste water from the cloves from Madagaskar containing: furfural $0.13 \%$, benzyl alcohol 0.05\%, methyl salicylate $0.29 \%$, 4-allilofenol $0.22 \%$, eugenol $89.21 \%$, $\beta$-caryophyllene $7.61 \%$, $\alpha$-caryophyllene $1.27 \%$, eugenyl acetate $0.87 \%$, $\beta$-caryophyllene oxide $0.35 \%$, 
the essential oil from the cloves from Madagaskar containing: methyl salicylate $0.10 \%$, 4 -allilofenol $0.20 \%$, eugenol $88.82 \%$, kopaen $0.23 \%$, $\beta$-caryophyllene $8.50 \%$, $\alpha$-caryophyllene $1.38 \%$, eugenyl acetate $0.57 \%$, $\beta$-caryophyllene oxide $0.19 \%$.

The studied compounds showed different antioxidant activity determined by DPPH method Table 1. Studies have shown that the values of the parameter determining the concentration reducing $50 \%$ of free radicals $\left(\mathrm{IC}_{50}\right.$ ) for eugenol are inversely proportional to its antioxidant activity, i.e. the lower the IC $\mathrm{C}_{50}$, the higher the antioxidant activity [10]. Eugenol $\left(\mathrm{IC}_{50}=6.09 \mu \mathrm{M}\right)$ had the highest activity. The value of the $\mathrm{IC}_{50}$ parameter for eugenol was more than 8 times lower than the value described in the literature for this compound $\left(\mathrm{IC}_{50}=50.44 \mu \mathrm{M}\right)$ [38]. In addition, as the concentration of eugenol in the test sample increased, the antioxidant activity increased from $49.90 \pm 0.003$ to 97.05 $\pm 0.001 \% R S A$. The antioxidant activity of eugenol increases with an increase in the concentration of this compound in the test sample, due to a reduced electron density on the oxygen atom of the phenolic group (i.e. the -OH group bonded to the carbon of the aromatic ring). The hydrogen bonding energy is much lower, which makes it easier to give it to the DPPH radical (through the reaction of the radical and antioxidant molecule with the formation of the adduct) - Table 1.

The results of EDChA antioxidant activity presented in Table 1, showed that the value of the antioxidant activity may be strongly influenced by the kinetic behavior of this compound. While increasing the concentration of eugenyl dichloroacetate in the test sample, a decrease in antioxidant activity was observed: from $72.85 \pm 0.001$ (for ester concentration of $0.006 \% \mathrm{w} / \mathrm{v}$ ) to $16.31 \pm 0.002$ (for ester concentration of $50.000 \% \mathrm{w} / \mathrm{v})$. The reason for under-activation is that the reaction time (10 minutes) between DPPH and EDChA is too short. As a result, this time seems to prevent the end of the reaction between radical and antioxidant. This phenomenon is often observed in the case of antioxidants (essential oils, compounds isolated from plant materials or plant extracts) characterized by a slow reaction with DPPH radical [10,39-41]. Underestimated values of antioxidant activity caused by slow reaction of the antioxidant with DPPH radical were observed during the measurements of antioxidant activity of clove oil extracted from the clove buds of Syzygium aromaticum by steam distillation - Table 2 . The study showed that during the 10-minutes reaction the antioxidant activity of the oil was $89.04 \pm 0.001 \%$ RSA. By extending the reaction time (DPPH with this antioxidant) to 60 minutes, the antioxidant activity of the oil increased by almost $10 \%$ to $98.92 \pm$ $0.001 \%$ RSA. The choice of a proper reaction time is extremely important for EDChA, because characterized by a slow kinetic behavior (just like essential oils DChAA did not show antioxidant activity in the tested concentration range.

The antioxidant activity of antioxidants depends on DPPH radical concentration. Fadda et al [39] estimated the \% of unresponse DPPH during the reaction between DPPH and Java green tea, in systems with increasing DPPH concentration and with a constant ratio of DPPH/Java green tea. The amount of water in the system was very low $(5 \%)$ and its effect on the reactivity of DPPH was considered to be negligible. The amount of unresponsive DPPH radical decreases with increasing initial DPPH concentrations in the reaction environment. The highest concentration of unreacted DPPH was observed for the lowest initial radical concentration applied. Additionally, the increase in the initial DPPH concentration decreased the amount of unresponsive DPPH [39-42]. Our research showed that with an increase of DPPH radical concentration, the antioxidant activity of clove water almost doubled - Table 2. The antioxidant activity along with the prolongation of the reaction time between DPPH radical and antioxidant (i.e. with the decrease of DPPH concentration in the reaction environment) decreased from $33.02 \pm 0.000 \%$ RSA (at 10 minutes) to $16.77 \pm 0.004 \%$ RSA (at 60 minutes).

\subsection{Measurement of the Antioxidant Capacity and Skin Permeation Studies of Cosmetic Formulations}

Tables 3 presents the results for the antioxidant activity of cosmetic formulations containing of eugenol, clove oils, EDChA and DChAA, carried out by the DPPH method. 
Table 3. Antioxidant activity of cosmetic formulations.

\begin{tabular}{|c|c|c|c|}
\hline \multirow{2}{*}{$\begin{array}{l}\text { Sample } \\
\text { number }\end{array}$} & \multirow{2}{*}{ Cosmetic formulation containing } & \multicolumn{2}{|c|}{${ }^{*}$ Antioxidant activity (DPPH method): } \\
\hline & & $\%$ RSA10 & $\%$ RSA $_{60}$ \\
\hline 1 & Pure with distilled water & n.a. & n.a. \\
\hline 2 & **Pure with clove water & $8.16 \pm 0.009$ & $9.89 \pm 0.012$ \\
\hline 3 & $\mathrm{a}^{* *}$ Eugenol & $12.21 \pm 0.029$ & $37.99 \pm 0.084$ \\
\hline 4 & $\mathrm{a}^{* *}$ Clove oil from Madagascar & $12.31 \pm 0.000$ & $40.76 \pm 0.005$ \\
\hline 5 & $\mathrm{a}^{* *} \mathrm{EDChA}$ & $16.63 \pm 0.004$ & $38.02 \pm 0.006$ \\
\hline 6 & $\mathrm{a}^{* *} \mathrm{DChAA}$ & $12.04 \pm 0.350$ & $18.49 \pm 0.006$ \\
\hline 7 & $\mathrm{~b}^{* *}$ Eugenol & $10.88 \pm 0.006$ & $23.35 \pm 0.044$ \\
\hline 8 & $\mathrm{~b}^{* *}$ Clove oil from Madagascar & $7.07 \pm 0.003$ & $19.82 \pm 0.017$ \\
\hline 9 & $\mathrm{~b}^{* *}$ EDChA & $16.21 \pm 0.022$ & $33.20 \pm 0.027$ \\
\hline 10 & $\mathrm{~b}^{* *} \mathrm{DChAA}$ & $9.14 \pm 0.012$ & $12.72 \pm 0.025$ \\
\hline 11 & $\mathrm{c}^{* *}$ Eugenol & $10.66 \pm 0.002$ & $20.92 \pm 0.002$ \\
\hline 12 & $\mathrm{c}^{* *}$ Clove oil from Madagascar & $8.15 \pm 0.003$ & $20.76 \pm 0.017$ \\
\hline 13 & $\mathrm{c}^{* *} \mathrm{EDChA}$ & $16.99 \pm 0.002$ & $24.27 \pm 0.000$ \\
\hline 14 & $c^{* *}$ DChAA & $15.41 \pm 0.003$ & $24.40 \pm 0.002$ \\
\hline 15 & $\mathrm{~d}^{* *}$ Eugenol & $22.45 \pm 0.004$ & $59.60 \pm 0.003$ \\
\hline 16 & $\mathrm{~d}^{* *}$ Clove oil from Madagascar & $17.07 \pm 0.004$ & $34.80 \pm 0.018$ \\
\hline 17 & $\mathrm{~d}^{* *}$ EDChA & $20.75 \pm 0.003$ & $41.50 \pm 0.007$ \\
\hline 18 & ***Pure with clove water & $16.36 \pm 0.009$ & $18.19 \pm 0.012$ \\
\hline 19 & $\mathrm{~d}^{* * *}$ Eugenol & $31.48 \pm 0.005$ & $65.53 \pm 0.009$ \\
\hline 20 & $\mathrm{~d}^{* * *}$ Clove oil from Indonesia & $32.99 \pm 0.002$ & $66.78 \pm 0.016$ \\
\hline 21 & $\mathrm{~d}^{* * *}$ EDChA & $25.25 \pm 0.003$ & $49.50 \pm 0.003$ \\
\hline $\begin{array}{l}{ }^{*} \text { Mean } \pm \text { S.I } \\
* * \text { clove wat } \\
* * * \text { clove wo } \\
\text { a the cosmet } \\
\text { screwed int } \\
b \text { the relevar } \\
\text { formulation } \\
\text { c the relevar } \\
\text { formulation } \\
\text { d the cosmet } \\
\text { into it, } \\
\text { n.a. - no act }\end{array}$ & $\begin{array}{l}\mathrm{n}=3) \text {, } \\
\text { which is a waste from the steam disti } \\
\text { ormich is a waste from the steam dis } \\
\text { ormulation was first obtained and the } \\
\text { ctive substance was added to the org } \\
\text { ormulation was first obtained and the } \\
\text { y. }\end{array}$ & $\begin{array}{l}\text { on of cloves frc } \\
\text { tion of cloves } f \\
\text { he relevant acti } \\
\text { phase during } \\
\text { phase during } \\
\text { he relevant acti }\end{array}$ & $\begin{array}{l}\text { r, } \\
\text { as (with a recipe mixer) } \\
\text { nof the cosmetic } \\
\text { as (manually) screwed }\end{array}$ \\
\hline
\end{tabular}

Tables 4 presents the results for the antioxidant activity of solutions of the tested cosmetic formulations containing of eugenol, EDChA and DChAA. 
Table 4. Antioxidant activity of solutions of the tested cosmetic formulations evaluated with DPPH, ABTS and Folin-Ciocalteu methods.

\begin{tabular}{|c|c|c|c|c|}
\hline \multirow{3}{*}{$\begin{array}{l}\text { Sample } \\
\text { number }\end{array}$} & \multirow{3}{*}{$\begin{array}{l}\text { Cosmetic formulation } \\
\text { containing }\end{array}$} & $\begin{array}{c}\text { Cosmetic } \\
\text { formulation } \\
\text { applied to the skin }\end{array}$ & $\begin{array}{l}\text { Acceptor fluid } \\
\text { after } 24 \text { hours of } \\
\text { penetration }\end{array}$ & $\begin{array}{c}\text { Solution after skin } \\
\text { extraction }\end{array}$ \\
\hline & & \multicolumn{3}{|c|}{${ }^{*}$ Antioxidant activity (DPPH method): } \\
\hline & & \multicolumn{3}{|c|}{$\mathrm{mmol} \mathrm{TE} / \mathrm{dm}^{3}(\%$ RSA $)$} \\
\hline 1 & Pure with distilled water & n.a. & n.a. & n.a. \\
\hline 11 & $\mathrm{c}^{* *}$ Eugenol & $0.041 \pm 0.002(10.66)$ & $>0.001(0.77)$ & $0.011 \pm 0.002(4.03)$ \\
\hline 13 & ${ }^{* * *}$ EDChA & $0.083 \pm 0.001(16.99)$ & $>0.001(1.56)$ & $0.019 \pm 0.004(5.29)$ \\
\hline \multirow[t]{3}{*}{14} & $\mathrm{c}^{* *} \mathrm{DChAA}$ & $0.073 \pm 0.002(15.41)$ & $>0.001(1.13)$ & $0.021 \pm 0.004(5.56)$ \\
\hline & & \multicolumn{3}{|c|}{ *Antioxidant activity (ABTS method): } \\
\hline & & \multicolumn{3}{|c|}{$\mathrm{mmol} \mathrm{TE} / \mathrm{dm}^{3}(\%$ RSA $)$} \\
\hline 1 & Pure with distilled water & - & n.a. & n.a. \\
\hline 11 & ${ }^{* *}$ Eugenol & - & $0.088 \pm 0.014(8.81)$ & $0.377 \pm 0.018(20.31)$ \\
\hline 13 & $\mathrm{c}^{* *} \mathrm{EDChA}$ & - & $0.074 \pm 0.001(7.62)$ & $0.367 \pm 0.018(19.91)$ \\
\hline \multirow[t]{3}{*}{14} & $\mathrm{c}^{* *} \mathrm{DChAA}$ & - & $0.050 \pm 0.012(6.65)$ & $0.322 \pm 0.011(18.13)$ \\
\hline & & \multicolumn{3}{|c|}{ *Antioxidant activity(Folin-Ciocalteu method): } \\
\hline & & \multicolumn{3}{|c|}{$\mathrm{mmol} \mathrm{GA} / \mathrm{dm}^{3}(\%$ RSA $)$} \\
\hline 1 & Pure with distilled water & - & n.a. & n.a. \\
\hline 11 & $\mathrm{c}^{* *}$ Eugenol & - & $0.059 \pm 0.004$ & $0.226 \pm 0.010$ \\
\hline 13 & $\mathrm{c}^{* *} \mathrm{EDChA}$ & - & $0.075 \pm 0.011$ & $0.268 \pm 0.007$ \\
\hline 14 & $c^{* *}$ DChAA & - & $0.070 \pm 0.004$ & $1.196 \pm 0.003$ \\
\hline \multicolumn{5}{|c|}{$\begin{array}{l}\text { * Mean } \pm \text { S.D. }(\mathrm{n}=3) \text {, } \\
\text { ** clove water, which is a waste from the steam distillation of cloves from Madagascar, } \\
\text { c the relevant active substance was added to the aqueous phase during the preparation of the cosmetic } \\
\text { formulation, } \\
\text { n.a. - no activity. }\end{array}$} \\
\hline
\end{tabular}

Tables 5 presents the results of studies on the penetration and the accumulation of active substances contained in cosmetic formulations.

Table 5. Penetration of active substances (contained in cosmetic formulations) through skin and the amounts of extracted active ingredients accumulated in it.

\begin{tabular}{c|c|c|c}
\hline \multirow{2}{*}{$\begin{array}{c}\text { Sample } \\
\text { number }\end{array}$} & $\begin{array}{c}\text { Cosmetic } \\
\text { formulation } \\
\text { containing }\end{array}$ & $\begin{array}{c}\text { Mass of substance in the acceptor } \\
\text { fluid after 24 hours of penetration }\end{array}$ & $\begin{array}{c}\text { Concentration of substance } \\
\text { extracted from the skin }\end{array}$ \\
\cline { 3 - 4 } & ${ }^{*}$ Eugenol & $(\mu \mathrm{g})$ & $\left(\boldsymbol{\mu g} / \mathbf{c m}^{2}\right.$ skin) \\
\hline $\mathbf{1 1}$ & ${ }^{*}$ EDChA & $20.53 \pm 0.800^{\mathrm{a}}$ & $156.89 \pm 6.980^{\mathrm{b}}$ \\
\hline $\mathbf{1 3}$ & ${ }^{*}$ DChAA & $19.59 \pm 1.750^{\mathrm{a}}$ & $173.94 \pm 8.348^{\mathrm{b}}$ \\
\hline $\mathbf{1 4}$ & $14.209 \pm 1.450^{\mathrm{b}}$ & $251.49 \pm 9.200^{\mathrm{a}}$ \\
\hline
\end{tabular}

\footnotetext{
* Mean \pm S.D. $(n=3)$, different letters - values are significantly different, mass substance in the acceptor
} fluid $(\mathrm{P}<0.05)$, concentration of substance extracted from the skin $(\mathrm{P}<0.001)$.

Figures 1 and 2 show the results of studies on the permeation of cosmetic formulations containing active substances through pig skin during the 24-hour experiment and mass of test cosmetic formulation containing active substances in the acceptor fluid during the 24-hour experiment. 


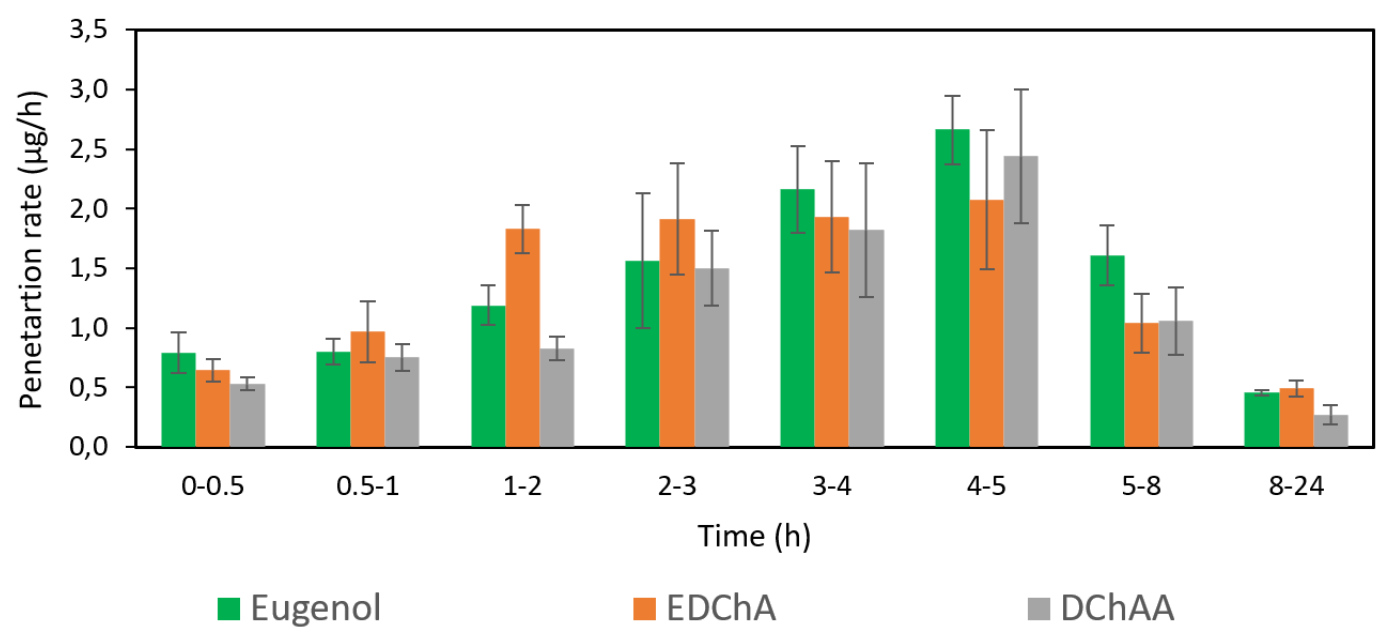

Figure 1. The penetration rate of Eugenol, EDChA, DChAA contained in test cosmetic formulation through the skin during the 24-hour experiment.

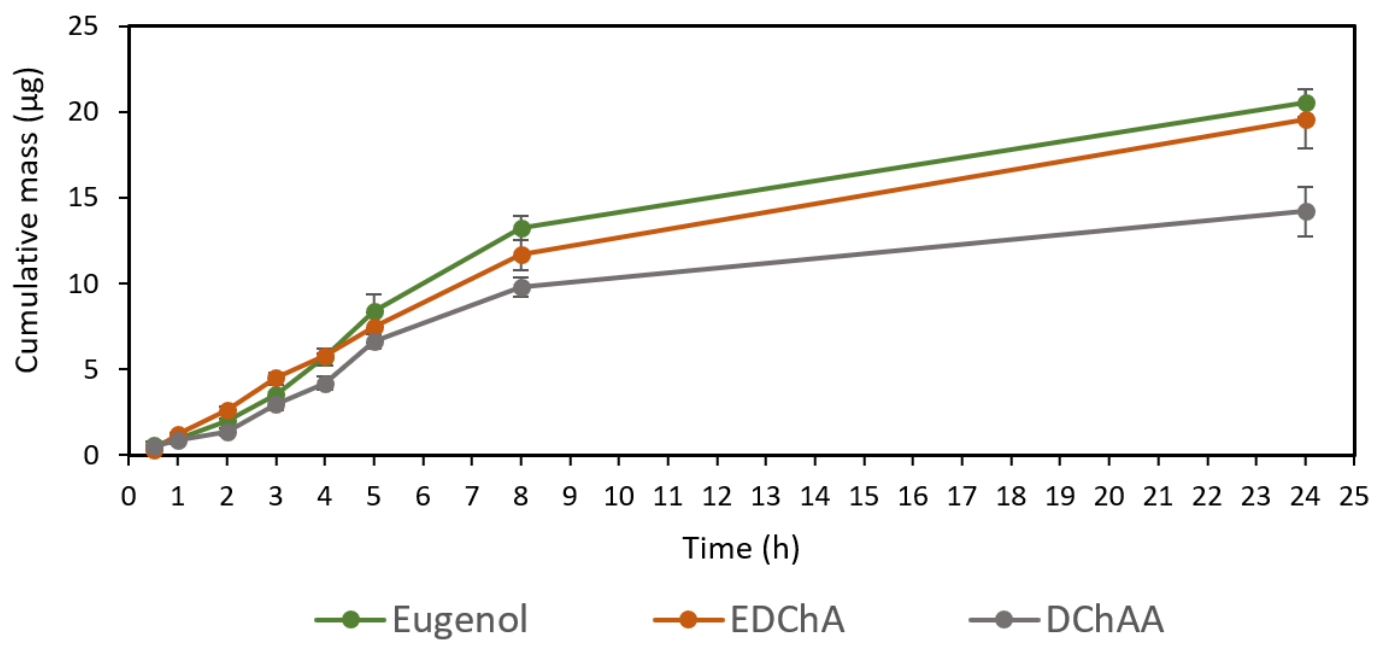

Figure 2. Cumulative mass of Eugenol, EDChA, DChAA contained in test cosmetic formulation penetrated into acceptor fluid during the 24-hour experiment.

The study of potential DPPH radical scavenging capacity of the pure preparation, containing no active substance (samples 1) and the formulation prepared with the use of clove water as postprocessing waste (samples 2 and sample 18) showed that samples 1 did not show antioxidant activity, while samples 2 and 18 were characterized by a DPPH radical scavenging degree of: $8.16 \pm 0.009 \%$ $\mathrm{RSA}_{10}$ and $9.89 \pm 0.012 \% \mathrm{RSA}_{60}$ and $16.36 \pm 0.009 \% \mathrm{RSA}_{10}$ and $18.19 \pm 0.012 \% \mathrm{RSA}_{60}$, respectively. Cosmetic formulations containing $1.000 \% \mathrm{w} / \mathrm{v}$ antioxidant (eugenol, clove oil from Madagascar or Indonesia, EDChA and DChAA) were characterized by efficacy to react with DPPH radical. The highest efficacy was shown by the preparations obtained in the following way: first a cosmetic preparation containing clove water was obtained, and then a suitable active substance (i.e. eugenol, a new eugenol ester derivative - EDChA and an essential oil obtained by hydrodistillation of clove from Indonesia) was added (manually) into the finished final preparation. Cosmetic formulations showed the highest efficiency to react with DPPH radical after 60 minutes of incubation. \%RSA for these samples decreased as follows: sample $20(66.78 \pm 0.016)>$ sample $19(65.53 \pm 0.009)>$ sample 15 $(59.60 \pm 0.003)>$ sample $21(49.50 \pm 0.003)$. Studies measuring the antioxidative potential of cosmetic 
formulations containing two different clove oils have shown different efficacy to react with the DPPH radical. The antioxidant activity of the preparation containing essential oil extracted from clove trees in Indonesia (sample 20) was almost twice as high as the antioxidant activity of the preparation containing essential oil extracted from clove trees in Madagascar (sample 16). The percentage of RSA after 10 and 60 minute incubation for these preparations was $32.99 \pm 0.002$ and $66.78 \pm 0.016$ and 17.07 \pm 0.004 and $34.80 \pm 0.018$, respectively - Table 3 . Reactive oxygen species (ROS) reduce the concentration of active glutathione (GSH), while increasing the concentration of reduced glutathione (GSSG), thus causing oxidative stress. Elevated levels of reduced glutathione have been observed in cancer cells. characterized by resistance to anticancer drugs. These cells do not undergo apoptosis, as a result of which the body's homeostasis is disturbed. From the modern oncology point of view, the process of apoptosis is very important because it protects the body from the proliferation of sick, mutated or damaged cells and leads to spontaneous death of cancer cells. Cosmetic preparations containing eugenol and other phenolic compounds present in isolated clove oils may enhance the activity of chemotherapeutic agents and induce apoptosis of cervical cancer cells without toxicity to healthy cells [49-50]. Moreover eugenol has a hydroxyl group (-OH) associated with an aromatic ring with acidic properties, which could lead to antioxidant activity. Its free radicals scavenging activity could lead to form phenolic radicals. These radicals are stable due to resonance caused by charge transfer and are not able to detach hydrogen from lipid or protein molecules (and to decrease the oxidation).

Replacement of hydrogen atoms in the aliphatic chain EDChA by heteroatoms (in this case, chlorine atoms) enhances the antioxidative properties. Eugenol esters containing chlorine atoms in the structure easily trap free radicals, giving up the $\mathrm{H}$ atom in the aliphatic chain. The reason is a change in the shape of the molecule, i.e. a change in length, direction, range and polarization of the bonds and a change in the symmetry of the particles. Introduction of chlorine atoms into the structure, causes polarization of bonds between carbon-chlorine atoms. The polarization of bonds between the carbon-chlorine atoms reduces the density of the electron cloud in the whole molecule and causes polarization of all close bonds present in the structure. As a result of this bond between the carbonhydrogen atoms in EDChA molecules, they change their length and polarity. In addition, the presence of chlorine atoms in the structure of EDChA changes the electro-neutrality of carbon atoms. Moreover, the presence of the methoxy group $\left(-\mathrm{OCH}_{3}\right)$ in the eugenol and its ester increases the antioxidant properties of these compounds [54].

In the case of studies carried out for pure preparation with distilled water instead of antioxidant solution (Table 4), no antioxidant activity was shown (cosmetic formulation applied to the skin, acceptor fluid after 24 hours of penetration, solution after skin extraction). The test results, presented in Table 4, show that solutions of acceptor fluids containing eugenol, EDChA and DChAA were characterized by antioxidant activity evaluated with DPPH, ABTS and Folin-Ciocalteu methods. The degree of reduction of the DPPH free radical (of acceptor fluid solutions collected after 24 hours of permeation) increased in the following order: 1.56 (for cosmetic formulation containing EDChA) > 1.13 (in the case of cosmetic formulation containing DChAA) $>0.77 \%$ RSA (for cosmetic formulation containing eugenol). The antioxidant activity (determined by the ABTS method) of acceptor fluid collected after 24 hours of permeation showed that the cosmetic formulation containing eugenol had the highest antioxidant activity (8.81\% RSA). Lower antioxidant activity was observed for the formulation with EDChA and DChAA (7.62 and 6.65\% RSA) - Table 4. The polyphenol contents (obtained by the Folin-Ciocalteu method) in acceptor fluid (collected after 24 hours of permeation) showed that the tested cosmetic formulation containing EDChA had the highest polyphenol content $\left(0.075 \pm 0.011 \mathrm{mmol}\right.$ gallic acid $\left./ \mathrm{dm}^{3}\right)$. Lower concentrations of $0.070 \pm 0.004$ and $0.059 \pm 0.004 \mathrm{mmol}$ of gallic acid $/ \mathrm{dm}^{3}$, respectively, were found for cosmetic formulation containing DChAA and eugenol (Table 4).

The results of studies on the antioxidant activity of solutions of skin extracts obtained after the experiment showed that cosmetic formulations containing DChAA, eugenol and its ester derivative were characterized by antioxidant activity, as estimated by the three techniques mentioned: DPPH, ABTS, and Folin-Ciocalteu. The degree of DPPH free radical reduction for these preparations 
decreased in the following order: DChAA (5.56) > EDChA (5.29) > eugenol (4.03\% RSA) - Table 4. In contrary, the antioxidant activity (ABTS method) of the solutions obtained after skin extraction decreased as follows: 20.31 (for cosmetic formulation with eugenol) $>19.91$ (for cosmetic formulation with EDChA) > 18.13 (for cosmetic formulation with DChAA) (Table 4). The results obtained by the Folin-Ciocalteu method showed that the values of antioxidant activity of solutions obtained after skin extraction (cosmetic formulations containing EDChA and eugenol) were higher $(0.268 \pm 0.007$ and $0.226 \pm 0.010 \mathrm{mmol}$ of gallic acid $\left./ \mathrm{dm}^{3}\right)$ than the values of antioxidant activity of cosmetic formulations containing DChAA (1.196 $\pm 0.003 \mathrm{mmol}$ gallic acid/ $\left./ \mathrm{dm}^{3}\right)$ (Table 4).

In HIV-infected patients the occurrence of oxidative stress and significantly lower antioxidant concentrations were observed than in non-HIV individuals. In HIV individuals a reduced plasma GSH concentration, increased PP (peroxidation potential), MDA (malondialdehyde) and HPO (total hydroperoxides) concentrations and altered CAT (catalase) and SOD (superoxide dismutase) activity have been reported [51]. The reason of the antioxidant deficiency during HIV infection may be malabsorption of antioxidants, as well as enhanced cysteine metabolism with a consequent loss of thiol groups. The treatment with anti-cancer antioxidants, protects, among others, thiol groups of proteins from irreversible inactivation caused by ROS. The application of antioxidants in the first weeks after HIV infection was detected might cause the disease regress [46, 47].

Numerous literature reports have shown that neurodegenerative diseases that are caused by reactive oxygen species are Alzheimer's and Parkinson's disease. The brain of people suffering from Alzheimer's is constantly exposed to ROS, resulting in the formation of A $\beta$-amyloid, the peptide responsible for the formation of senile plates. $A \beta$-amyloid induces the formation of intracellular ROS, causes protein oxidation, lipid peroxidation, increase in GSSG concentration and decrease in S-glutathione transfer activity. In Parkinson's disease, dopamine is converted by monoamine oxidase (MAO), which results in the accumulation of hydrogen peroxide, reacting with reactive oxygen species and leads to gradual degeneration and disappearance of the gray matter [48-50].

In our own research conducted in vitro, the penetration of cosmetic formulation containing eugenol and its new ester derivative (EDChA) through pig skin was assessed. For comparative purposes, tests were also carried out for pure DChAA. The experiment was carried out using a Franz diffusion chamber, in which the donor phase consisted of the formulations tested. The acceptor phase was PBS solution, because it corresponds to systemic conditions, is isotonic in nature, and allows conditions corresponding to the conditions prevailing in the deeper layers of the skin to be maintained [51]. Permeation of test substances (contained in cosmetic formulations) through pig skin into the acceptor fluid increased in the following order: eugenol > EDChA > DChAA. After conducting the experiment for 24 hours, the highest average cumulative mass was observed in the case of eugenol $(20.53 \pm 0.800 \mu \mathrm{g})$. The mass was slightly lower in the case of EDChA $(19.59 \pm 1.750$ $\mu \mathrm{g})$. In addition, the study showed that amount of eugenol and EDChA penetration differed from that of DChAA $(14.209 \pm 1.450 \mu \mathrm{g})$ - Table 5 . The highest increase in the penetration rate of cosmetic formulations containing eugenol, EDChA and DChAA to the acceptor fluid $(\mu \mathrm{g} / \mathrm{h})$ were observed between 4 and 5 hours (Fig. 1), while for pure EDChA between 2 and 3 hours, pure eugenol it was between 3 and 4 hours [18]. Pure dichloroacetic acid accumulated in the skin [18]. The factor significantly affecting the transport of active substances is the lipophilicity of the test compound. The optimal $\log \mathrm{P}$ coefficient (which is an indicator of the lipophilicity of the active substance) is in the range of 2 to 3 [32, 52]. This was also confirmed in the publication [18], which showed that both eugenol and its ester derivative were characterized by good permeability through the skin $(\log \mathrm{P}$ : eugenol $2.20 \pm 0.001$, EDChA $2.65 \pm 0.001$ ). Lipophilic compounds penetrate much more easily through the skin, because the skin consist mainly of lipid substances which, at the same time, limits the penetration of hydrophilic substances (among others dichloroacetic acid, whose $\log \mathrm{P}$ is $0.95 \pm$ 0.002) [53]. The lower lipophilicity of the compound $(\log \mathrm{P}<2)$ is associated with its worse penetration the skin [33]. This relationship was also confirmed in our publication [18]; the average masses accumulated in the acceptor fluid after 24 hours were $272.89 \pm 54.64 \mu \mathrm{g}$ (in the case of eugenol), 302.77 $\pm 1.90 \mu \mathrm{g}$ (in the case of EDChA), $247.63 \pm 16.45 \mu \mathrm{g}$ (in the case of DChAA), while the average 
cumulative masses for formulations containing these compounds at $0.5 ; 1 ; 2 ; 3 ; 4 ; 5 ; 8$, and 24 hours are shown in Fig. 2.

After the experiment was carried out, the skin was extracted in order to extract the tested active ingredients accumulated in it. The obtained test results showed that the concentration of substances (contained in the tested formulations) in the analyzed extracts decreased in the following order: DChAA $\left(251.49 \pm 9.200 \mu \mathrm{g} / \mathrm{cm}^{2} \mathrm{skin}\right)>$ EDChA $\left(173.94 \pm 8.348 \mu \mathrm{g} / \mathrm{cm}^{2} \mathrm{skin}\right)>$ eugenol $(156.89 \pm 6.980$ $\left.\mu \mathrm{g} / \mathrm{cm}^{2} \mathrm{skin}\right)$. Pure DChAA was accumulated in the skin, as evidenced by the high concentration of compound found in the analyzed extract: DChAA $750.82 \pm 44.62 \mu \mathrm{g} / \mathrm{cm}^{2}$ skin [18].

\section{Conclusions}

In case of antioxidants rapidly reacted with DPPH radical (such as eugenol - Table 1) the concentration reducing $50 \%$ of free radicals ( $\mathrm{IC}_{50}$ ) is not affected by the reaction time [34-35]. This observation differ from dichloroacetate eugenyl. which is characterized by a slow kinetic effect (similarly to clove oil extracted from the cloves) - Tables 1 and 2. For these reasons reaction time measurements should be carried out individually for each antioxidant to complete the reaction between antioxidant and DPPH radical. The antioxidant activity of aqueous solution of antioxidants (i.e. clove water - Table 2) is affected by DPPH concentration in the reaction environment - the higher the initial DPPH concentration the lower \% of unreacted radical was observed in the reaction environment [34-36].

We demonstrated that cosmetic formulations containing eugenol, new eugenol derivative (EDChA) and DChAA, penetrate through biological membranes. EDChA is characterised by higher partition coefficient compared to DChAA, which can have a positive impact on enhance active substance transport through biological membranes. Eugenol is a terpene compound classified as an absorption promoter that is characterized by high antibacterial as well as antioxidant activity. Terpenes, which are a group of substances that are commonly considered safe from the point of view of dermal toxicity, are often used in preparations applied to the outer layer of the skin $[5,8,9,11,18]$.

The transport of the active substance (contained in the cosmetic formulation) the skin also depends on the molecular weight of the active substance itself. Overcoming the lipophilic barrier, which is the skin, is possible for eugenol and non-polar - new ester of eugenol, which have molecular weights of $<600 \mathrm{Da}[18,45,54,58]$. Besides better absorption of active substance by penetrating faster, the presented cosmetic formulations can provide endogenous action against free radicals, which is their superiority to the used in cosmetology pure acids ( $\alpha$ - and $\beta$-hydroxy acids, TChAA), for which the skin is a barrier limiting their penetration $[18,46,49,53,58]$. In addition, the good permeability of cosmetic formulations containing eugenol, EDChA and DChAA through the skin and their proper accumulation in the skin (Table 5, Fig. 1, Fig. 2) as well as their antioxidant capacity (Table 4) can limit also the exogenous effects of free radicals. Although eugenol, as a biologically active substance, is already used in many cosmetic and pharmaceutical preparations the antioxidant effect of eugenol after crossing the skin barrier has not previously been studied.

The results of the conducted research showed that among the tested cosmetic formulations the highest antioxidant activity determined with DPPH method was found for formulations containing EDChA (Table 1) as an active substance and clove water (aqueous fraction containing furfural, benzyl alcohol, methyl salicylate, 4 -allilofenol, eugenol, $\beta$-caryophyllene, $\alpha$-caryophyllene, eugenyl acetate, $\beta$-caryophyllene oxide) as a water phase. These compounds, due to their mechanism of action, can have a beneficial effect on the balance between oxidants and antioxidants in the body, minimizing the effects of oxidative stress. Moreover, they seem to be effective agents with potential application among others in the prevention of cancer owing their antiproliferative and anti-angiogenic activity. Due to the content of phenolic compounds (eugenol) they may also show chemopreventive activity and affect the induction of cancer cell apoptosis [42-57]. 
Author Contributions: Conceptualization. E.M. and A.N.; Writing-review \& editing. E.M.. A.N. and A.G.; Methodology. E.M.. A.N.. W.D. and Ł.K.; Reviewing R.P. and A.K.; Formal analysis. A.N.. E.M. and Ł.K.; Investigation A.N.. Ł.K. and E.M; Writing-original draft. A.N. and E.M.; Supervision. A.K. and R.P.

Funding: Presented here research received external funding in project "ZUT 2.0 - Modern Integrated University" grant number POWR.03.05.00-00-Z205/17.

Conflicts of Interest: Declare conflicts of interest or state "The authors declare no conflict of interest."

$\begin{array}{ll}\text { Abbreviations: } \\ \text { The following abbreviations are used in this manuscript: } \\ \text { EDChA } & \text { eugenyl dichloroacetate } \\ \text { DChAA } & \text { dichloroacetic acid } \\ \text { DPPH } & \text { 2.2-diphenyl-1-picrylhydrazyl } \\ \text { ABTS } & \text { 2.2'-azino-bis(3-ethylbenzothiazoline-6-sulfonic acid) } \\ \text { ROS } & \text { reactive oxygen species } \\ \text { NF- } \kappa \text { B } & \text { nuclear factor } \\ \text { P } & \text { partition coefficient } \\ \text { IC50 } & \text { the concentration reducing 50\% of free radicals } \\ \text { GSH } & \text { glutathione } \\ \text { GSSG } & \text { reduced form glutathione } \\ \text { PP } & \text { peroxidation potential } \\ \text { MDA } & \text { malondialdehyde } \\ \text { HPO } & \text { total hydroperoxides } \\ \text { CAT } & \text { catalase } \\ \text { SOD } & \text { superoxide dismutase } \\ \text { MAO } & \text { monoamine oxidase }\end{array}$

\section{References}

1. Gautam, N.; Mantha, A.K.; Mittal, S. Essential oils and their constituents as anticancer agents: a mechanistic view. Biomed. Res. Int. 2014, 2014, 1-23.

2. Kaur, K.; Kaushal, S.; Rani, R. Chemical composition, antioxidant and antifungal potential of clove (Syzygium aromaticum) essential oil, its major compound and its derivatives. J. Essential Oil Bearing Plants 2019, 22 (5), 11951217.

3. Perricone, M.; Arace, E.; Corbo, M.R.; Sinigaglia, M.; Bevilacqua, A. Bioactivity of essential oils: a review on the interaction with food components. Front. Microbiol. 2015, 6 (76), 1-7.

4. Pavithra, P.S.; Mehta, A.; Verma, R.S. Essential oils: from prevention to treatment of skin cancer. Drug Disc. Today. 2019, 24, 644-655.

5. Choi, R.; Shin, S.H.; Kim, U.K.; Hong, J.W.; Kim, G.C.S.; S phase cell cycle arrest and apoptosis is induced by eugenol in G361 human melanoma cells. Int. J. Oral Biol. 2011, 36, 129-134.

6. Jung, J.I.; Kim, E.J.; Kwon, G.T.; Jung, Y.J.; Park, T.; Kim, Y.; Yu, R.; Choi, M.S.; Chun, H.S.; Kwon, S.H.; Her, S.; Lee, K.W.; Park, J.H.Y. $\beta$-Caryophyllene potently inhibits solid tumor growth and lymph node metastasis of B16F10 melanoma cells in high-fat diet- induced obese C57BL/6N mice. Carcinogenesis. 2015, 36, 1028-1039.

7. Pavithra, P.S.; Mehta, A.; Verma, R.S. Synergistic interaction of $\beta$-caryophyllene with aromadendrene oxide 2 and phytol induces apoptosis on skin epidermoid cancer cells. Phytomedicine. 2018, 47, 121-134.

8. Jo, E.S.; Sp, N.; Kang, D.Y.; Rugamba, A.; Kim, I.H.; Bae, S.W.; Liu, Q.; Jang, K.J.; Yang. Y.M. Sulfur 
Compounds Inhibit High Glucose-Induced Inflammation by Regulating NF- $\kappa$ B Signaling in Human Monocytes. Molecules 2020, 25, 2-15.

9. Jaganathan, S.K.; Mazumdar, A.; Mondhe, D.; Mandal, M. Apoptotic effect of eugenol in human colon cancer cell lines. Cell Biology International. 2011, 35 (6), 607-615.

10. Park, K.R.; Nam, D.; Yun, H.M.; Lee, S.G.; Jang, H.J.; Sethi, G.; Cho, S.K.; Ahn, K.S. $\beta$-Caryophyllene oxide inhibits growth and induces apoptosis through the suppression of PI3K/AKT/mTOR/S6K1 pathways and ROS-mediated MAPKs activation. Cancer Letters. 2011, 312 (2), 178-188.

11. Deepak, V.; Kasonga, A.; Kruger, M.C.; Coetzee, M. Inhibitory effects of eugenol on RANKL-induced osteoclast formation via attenuation of NF- $\kappa$ B and MAPK pathways. Connective Tissue Research. 2015, 56 (3), 195-203.

12. Michalak, A.; Krzeszowiak, J.; Markiewicz-Górka, I. The correlations between aging of the human body. oxidative stress and reduced efficiency of repair systems. Postepy Hig. Med. Dosw. 2014, 68, 1483-1491.

13. Igielska-Kalwat, J.; Gościańska, J.; Nowak, I. Carotenoids as natural antioxidants. Postępy Hig. Med. Dośw. 2015, 69, 418-428.

14. Agati, G.; Azzarello, E.; Pollastri, S.; Tattini, M. Flavonoids as antioxidants in plants: Location and functional significance. Plant Sci. 2012, 196, 67-76.

15. Zhao, J. Flavonoid transport mechanisms: How to go. and with whom. Trends Plant Sci. 2015, 20 (9), 576585.

16. Suvarnakuta, P.; Chaweerungrat, C.; Devahastin, S. Effects of drying methods on assay and antioxidant activity of xanthones in mangosteen rind. Food Chem. 2011, 125 (1), 240-247.

17. Li, L.; Seeram., N.P. Maple syrup phytochemicals include lignans. coumarins. a stilbene. and other previously unreported antioxidant phenolic compounds. J. Agric. Food Chem. 2010, 58 (22), 11673-11679.

18. Makuch, E.; Nowak, A.; Günther, A.; Pełech, R.; Kucharski, Ł.; Duchnik, W.; Klimowicz, A. Enhancement of the Antioxidant and Skin Permeation Properties of Eugenol by the Esterification of Eugenol to New Derivatives, AMB Expr. 2020, AMBE-D-20-00355 - Accept 29.09.2020.

19. Nowak, A.; Klimowicz, A.; Duchniak, W.; Kucharski, Ł.; Florkowska, K.; Muzykiewicz, A.; Wira, D.; Zielonka-Brzezicka, J.; Siedłowska, A.; Nadarzewska, K. Application of green-extraction technique to evaluate of antioxidative capacity of wild population of fireweed (Epilobium angustifolium). Herba Pol. 2019, 65 (4), 18-30.

20. Kim, T.Y.; Leem, E.; Lee, J.M.; Kim, S.R. Control of Reactive Oxygen Species for the Prevention of Parkinson's Disease: The Possible Application of Flavonoids. Antioxidants. 2020, 9 (583), 1-27.

21. Dam, B.; Misra, A.; Banerjee, S. Role of Gut Microbiota in Combating Oxidative Stress. In Oxidative Stress in Microbial Diseases; Chakraborti. S.. Chakraborti. T.. Chattopadhyay. D. Shaha. C. Eds. Springer. Singapore 2019, 43-97.

22. Khan, A.; Ikram, M.; Hahm, J.R.; Kim, M.O. Antioxidant and Anti-Inflammatory Effects of Citrus Flavonoid Hesperetin: Special Focus on Neurological Disorders. Antioxidants. 2020, 9 (609), 1-15.

23. Anis, E.; Zafeer, M.F.; Firdaus, F.; Islam, S.N.; Khan, A.A.; Hossain, M.M. Perillyl alcohol mitigates behavioural changes and limits cell death and mitochondrial changes in unilateral 6-OHDA lesion model of Parkinson's disease through alleviation of oxidative stress. Neurotox. Res. 2020, 38 (2), 461-477.

24. Ansary, J.; Forbes-Hernández, T.Y.; Gil, E.; Cianciosi, D.; Zhang, J.; Elexpuru-Zabaleta, M.; Simal-Gandara, J.; Giampieri, F.; Battino, M. Potential Health Benefit of Garlic Based on Human Intervention Studies: A Brief Overview. Antioxidants. 2020, 9 (619), 1-37. 
25. Wadhwa, R.; Gupta, R.; Maurya, P.K. Oxidative Stress and Accelerated Aging in Neurodegenerative and Neuropsychiatric Disorder. Curr. Pharm. Des. 2019, 24, 4711-4725.

26. Hanafy, D.M.; Burrows, G.E.; Prenzler, P.D.; Hill, R.A. Potential Role of Phenolic Extracts of Mentha in Managing Oxidative Stress and Alzheimer's Disease. Antioxidants. 2020, 9 (631), 1-24.

27. Liguori, I.; Russo, G.; Curcio, F.; Bulli, G.; Aran, L.; Della-Morte, D.; Gargiulo, G.; Testa, G.; Cacciatore, F.; Bonaduce, D. Oxidative stress. aging. and diseases. Clin. Interv. Aging. 2018, 13, 757-772.

28. Lesgards, J.F.; Baldovini, N.; Vidal, N.; Pietri, S. Anticancer activities of essential oils constituents and synergy with conventional therapies: a review. Phytother. Res. 2014, 28, 1423-1446.

29. Hussain, A.; Brahmbhatt, K.; Priyani, A.; Ahmed, M.; Rizvi, T.A.; Sharma, C. Eugenol enhances the chemotherapeutic potential of gemcitabine and induces anticarcinogenic and anti-inflammatory activity in human cervical cancer cells. Cancer Biother. Radio. 2011, 26, 519-527.

30. Arung, E.T.; Matsubara, E.; Kusuma, I.W.; Sukaton, E.; Shimizu, K.; Kondo, R. Inhibitory components from the buds of clove (Syzygium aromaticum) on melanin formation in B16 melanoma cells. Fitoterapia. 2011, 82, 198-202.

31. Brand-Williams, W.; Cuvelier, M.E.; Berset, C.L.W.T. Use of free radical method to evaluate antioxidant activity. LWT - Food Sci Technol. 1995, 28, 25-30.

32. Janus, E.; Ossowicz, P.; Klebeko, J.; Nowak, A.; Duchnik, W.; Kucharski, Ł.; Klimowicz, A. Enhancement of ibuprofen solubility and skin permeation by conjugation with L-valine alkyl esters. RSC Adv. 2020, 10, 75707584.

33. Simon, A.; Amaro, M.I.; Healy, A.M.; Cabral, L.M.; de Sousa, VP. Comparative evaluation of rivastigmine permeation from a transdermal system in the Franz cell using synthetic membranes and pig ear skin with in vivo-in vitro correlation. Int. J. Pharm. 2016, 512 (1), 234-241.

34. Kopečná, M.; Macháček, M.; Prchalová, E.; Štěpánek, P.; Drašar, P.; Kotora, M.; Vávrová, K. Galactosyl pentadecene reversibly enhances transdermal and topical drug delivery. Pharm Res. 2017, 34 (10), 2097 2108.

35. Davies, D.J.; Ward, R.J.; Heylings, J.R. Multi-species assessment of electrical resistance as a skin integrity marker for in vitro percutaneous absorption studies. Toxicol. In Vitro. 2004, 18 (3), 351-358.

36. Nowak, A.; Zielonka-Brzezicka, J.; Pechaiko, D.; Tkacz, M.; Klimowicz, A. The evaluation of the antioxidant properties of Ginkgo biloba L leaves after the end of the growing season. Pom J Life Sci. 2017, 63 (1), 9-15.

37. Floegel, A.; Kim, D.O.; Chung, S.J.; Koo, S.I.; Chun, O.K. Comparison of ABTS/DPPH assays to measure antioxidant capacity in popular antioxidant-rich. Journal of Food Composition and Analysis. 2011, 24, 10431048.

38. Zhang, P.; Zhang. E.; Xiao. M.; Chen. Ch.; Xu. W. Enhanced chemical and biological activities of a newly biosynthesized eugenol glycoconjugate. eugenol $\alpha$-D-glucopyranoside. Appl Microbiol Biotechnol. 2013, 97, 1043-1050.

39. Fadda, A.; Serra, M.; Molinu, M.G.; Azara, E.; Barberis, A.; Sanna, D. Reaction time and DPPH concentration influence antioxidant activity and kinetic parameters of bioactive molecules and plant extracts in the reaction with the DPPH radical. Journal of Food Composition and Analysis. 2014, 35, 112-119.

40. Magalhaes, L.M.; Barreiros, L.; Maia, M.A.; Reis, S.; Segundo, M.A. Rapid assessment of endpoint antioxidant capacity of red wines through microchemical methods using a kinetic matching approach. Talanta. 2012, 97 (0), 473-483.

41. Ahmad, N.; Fazal, H.; Ahmad, I.; Abbasi, B.H. Free radical scavenging (DPPH) potential in nine Mentha 
species. Toxicol. Ind. Health. 2012, 28 (1), 83-89.

42. Cenobio-Galindo, A.J.; Pimentel-Gonzalez, D.J.; Razo-Rodrıguez, O.E.; Medina-Perez, G.; CarrilloInungaray, M.L.; Reyes-Munguıa, A.; Campos-Montiel, R.G. Antioxidant and antibacterial activities of a starch film with bioextracts microencapsulated from cactus fruits (Opuntia oligacantha). Food Sci Biotechnol. 2019, 28 (5), 1553-1561.

43. Prajapati, S.K.; Garabadu, D.; Krishnamurthy, S. Coenzyme Q10 Prevents Mitochondrial Dysfunction and Facilitates Pharmacological Activity of Atorvastatin in 6-OHDA Induced Dopaminergic Toxicity in Rats. Neurotox Res. 2017,31, 478-492.

44. Park, M.H.; Kim, D.H.; Lee, E.K.; Kim, N.D.; Im, D.S.; Lee, J.; Yu, B.P.; Chung, H.Y. Age-related inflammation and insulin resistance: a review of their intricate interdependency. Arch. Pharm. Res. 2014, 37, 1507-1514.

45. Rice-Evans, C.; Miller, N.J.; Paganga, G. Structure - antioxidant activity relationship of flavonoids and phenolic acids. Free Radical Biology and Medicine 1996, 20 (7), 933-956.

46. Albano, E.; Vidali. M. Immune mechanisms in alcoholic liver disease. Genes Nutr. 2010, 5, 141-147.

47. Haq, I.U.; Parveen, N.; Rajput, M.T.; Dahot, M.U. Comparative characteristics of micropropagated plantlets of banana from bbtv-infected explants to its normal and saline stressed cultures. Pak. J. Bot. 2012, 4 (3), 11271130.

48. Klugman, A.; Naughton, D.P.; Isaac, M.; Shah, I.; Petroczi, A.; Tabet, N. Antioxidant Enzymatic Activities in Alzheimer's Disease: The Relationship to Acetylcholinesterase Inhibitors. Journal of Alzheimer's Disease. 2012, 29, 1-8.

49. Kulczyński, B.; Sidor, A.; Gramza-Michałowska, A. Characteristics of Selected Antioxidative and Bioactive Compounds in Meat and Animal Origin Products. Antioxidants. 2019, 8 (335), 1-47.

50. Tiwari, S.C.; Soni, R.M. Alzheimer's Disease Pathology and Oxidative Stress: Possible Therapeutic Options. J Alzheimers Dis Parkinsonism. 2014, 4 (5), 1-10.

51. Alonso, C.; Rubioa, L.; Touriñob, S.; Martía, M.; Barbaa, C.; Fernández-Camposc, F.; Codercha, L.; Parraa, J.L. Antioxidative effects and percutaneous absorption of five polyphenols. Free Radic. Biol. Med. 2014, 75, 149-155.

52. Srinivas, U.S.; Tan, B.W.Q.; Vellayappan, B.A.; Jeyasekharan, A.S. ROS and the DNA damage response in cancer. Redox Biol. 2019, 25, 1-9.

53. Jaworska, M.; Sikora, E.; Ogonowski, J. Factors Influencing the Percutaneous Penetration of Active Ingerdients. Wiad. Chem. 2011, 65, 3-4.

54. Huang, M.Z.; Yang, Y.J.; Liu, X.W.; Qin, Z.; Li, J.Y. Aspirin Eugenol Ester Reduces $\mathrm{H}_{2} \mathrm{O}_{2}$-Induced Oxidative Stress of HUVECs via Mitochondria-Lysosome Axis. Oxidative Medicine and Cellular Longevity. 2019, 2019, 11 pages.

55. Brozovic, A.; Ambriović-Ristov, A.; Osmak, M. The relationship between cisplatin-induced reactive oxygen species. glutathione. and BCL-2 and resistance to cisplatin. Critical Reviews in Toxicology. 2010, 40 (4), 347359.

56. Gil, L.; Tarinas, A.; Hernández, D.; Riverón, B.V.; Pérez, D.; Tápanes, R.; Capo, V.; Pérez, J. Altered oxidative stress indexes related to disease progression marker in human immunodeficiency virus infected patients with antiretroviral therapy. Biomedicine \& Aging Pathology. 2011, 1, 8-15.

57. Matsuda, E.M.; Colpas, D.R.; Campos, N.C.; Coelho, L.P.O.; dos Santos Carmo. A.M.; de Macedo Brígido. L.F. Undiagnosed acute HIV infection identified through RNA testing of pooled serum samples obtained 
during a dengue outbreak in São Paulo. Brazil. Rev Soc Bras Med Trop. 2017, 50 (1), 110-112.

58. Malinowska, M.; Sikora, E.; Ogonowski, J. Percutaneous penetration of active cosmetics ingredients. Wiad. Chem. 2013, 67, 3-4. 